\title{
Optimization of Alumina Slurry for Oxide-Oxide Ceramic Composites Manufactured by Injection Molding
}

\author{
Catherine Billotte, Edith Roland Fotsing, and Edu Ruiz \\ NSERC-Safran Chair on 3D Composites for Aerospace, Department of Mechanical Engineering, École Polytechnique de Montréal, \\ P.O. Box 6079, Centre-Ville Station, Montréal, QC, Canada H3C 3A7 \\ Correspondence should be addressed to Catherine Billotte; catherine.billotte@polymtl.ca
}

Received 13 March 2017; Revised 8 June 2017; Accepted 5 July 2017; Published 7 August 2017

Academic Editor: Marco Rossi

Copyright (C) 2017 Catherine Billotte et al. This is an open access article distributed under the Creative Commons Attribution License, which permits unrestricted use, distribution, and reproduction in any medium, provided the original work is properly cited.

\begin{abstract}
This paper focuses on the rheological study of an alumina suspension intended for the manufacturing of oxide-oxide composites by flexible injection. Given the production constraints, it is required to have stable suspension with low viscosity and a Newtonian behavior. This is achieved with a concentration of nitric acid between $0.08 \mathrm{wt} \%$ and $0.2 \mathrm{wt} \%$ and amount of $3 \mathrm{wt} \%$ of PVA binder. The maximum loading of the suspension of $47 \mathrm{vol} \%$ suggests that there is no structure development within the suspension with optimized concentration of acid and PVA.
\end{abstract}

\section{Introduction}

In the last decades, ceramic matrix composites (CMC) have been increasingly used in various engineering fields such as aerospace (rocket engine nozzle and gas turbines) and automobile (brake pads). Due to the ceramic based matrix, these materials can withstand high temperatures in oxidizing and corrosive environment. Nowadays, efforts focus on cost reduction and the improvement of CMC durability, notably for application in gas turbine engines. Moreover, CMC are more efficient in terms of energy and the light weight of these materials limits the emission of pollutants. Therefore, CMC are viable replacement for superalloys.

The presence of reinforcement not only guarantees the proper load transfer but reduces also the brittleness which characterizes ceramic materials. In fact, fiber reinforcement in CMC contributes to crack deflection, increasing therefore the hardness of the material. The compatibility between matrix and fiber maximizes the mechanical properties and limits the damage tolerance [1-3]. However, because of the crack propagation mechanism, it is necessary that the interphase between the matrix and the fiber is sufficiently weak to allow debonding and the relaxation of the stress at the crack tip. In oxide/oxide composites, there are two ways to promote the debonding during crack propagation of the matrix: by the use of a fugitive interphase which induces small gap between the matrix and the fiber or by the use of a porous interphase. This latter leads to lowering the elastic properties and the fracture energy $[3,4]$. Also, the use of continuous fibers as the reinforcement helps to increase the inelastic deformation at the fiber-matrix interface, improving strength in the presence of holes and notches [5].

Another major concern in the manufacture of CMC is oxidation during sintering or when it is subjected to high temperature stresses greater than $1000^{\circ} \mathrm{C}$. The diffusion of oxygen can potentially be limited at the interface by adding additives to the matrix. However, the use of oxide-based composites can overcome these limitations. Oxide/oxide composites are more resistant to oxidation [1] and exhibit comparable mechanical properties (creep performance) to other $\mathrm{CMC}$ such as $\mathrm{SiC} /$ carbon.

The manufacturing of oxide/oxide ceramic by flexible injection $[6,7]$ requires the use of oxide ceramic slurry. The particles in suspension must be able to fill the mold containing the oxide reinforcement. Thus, understanding mechanisms such as the colloid stability, dispersion, and rheology are important. Homogeneous distribution of uniform particles in the matrix can promote CMC with homogeneous distribution of the micropores and minimize the shrinkage during the drying and sintering processes $[8,9]$. It is therefore 
important to adjust the rheology of the slurry to ensure proper infiltration of the powder in strands $[2,5,10]$. This infiltration into the reinforcement requires a suspension with a high density of evenly distributed particles in terms of flocculation. Moreover, this requires the use of the dispersing agent and the binder in proper concentration.

While the viscosity of the suspension is among the most important criteria, the shear stress required to displace the suspension must be also considered. It was shown that, depending on $\mathrm{pH}$ of the suspension, the particles content, and the dispersant, flow rheology can change drastically from Newtonian behavior to shear thinning or thickening [8-12].

The main challenge with submicron particles remains the small separation distance, especially if the suspension is highly concentrated. A direct consequence of this small distance (less than 5 microns) is the slow settlement under gravity because Brownian motion keeps particles suspended [8]. However, due to the attractive Van der Waals force, small particles have a larger diffusion constant and thus higher probability of aggregation $[8,11,13]$. Then it is necessary to use a repulsive barrier to prevent aggregation. A wide variety of dispersants is available commercially and the choice depends not only on the type of particles, but also on the manufacturing process of CMC. There are several ways to provide repulsion between particles and overcome Van der Waals forces; however steric stabilization is particularly effective in organic liquids and aqueous solvents [13].

Polyelectrolytes and polymers are largely used as steric stabilizers in the literature [14-16]; however the long chain molecules may induce bridging and increase the viscosity of the suspensions. The bridging effect also increases with the reduction of the particle size. Several studies reported the use of small molecules such as ascorbic acid [11], citric acid $[17,18]$, or nitric acid [19-21] for the dispersion of alumina particles. The adsorption of the molecules occurs between its ionic functional group and the charged oxide of the alumina particle through a ligand exchange process $[8,11]$.

In order to increase the strength of the green body and being able to get a high density ceramic, a binder must be added to the suspension. The binder is typically a long chain polymer which is adsorbed at the surface of the particles and that can create bridges between the particles through hydrogen bonding $[8,16,22]$. Literature reports the use of cellulose derivatives such as hydroxyethyl cellulose and polyvinyl alcohol $[14,15,21,23-25]$. When these types of binder are dispersed into water, a gel structure is formed and its action depends on the concentration of particles and level of dispersion. Depending on its molecular weight and quantity, it can strongly affect the rheology of the suspension. There are several factors to take into account when choosing the binder and its burnout characteristics. The binder should be compatible with the slurry and should not displace the dispersant from the particle surface. Additionally, for oxides, it should be less polar than the dispersant [13]. It is necessary to optimize the amount of the binder to form a ceramic cake that can be easily demolded after processing [14].

This paper deals with the influence of PVA, nitric acid, as well as the particles size, and solid loading on the dispersion of $\alpha-\mathrm{Al}_{2} \mathrm{O}_{3}$ slurry. Since the suspension is used as matrix for oxide/oxide processing by flexible injection, the impact of mixing procedure and shear stress on the viscosity will be also assessed and discussed.

\section{Materials and Methods}

2.1. Materials and Suspension Preparation. The suspensions used in this work were made of $\alpha-\mathrm{Al}_{2} \mathrm{O}_{3}$ powder with a BET specific surface of $10 \mathrm{~m}^{2} / \mathrm{g}$ and average particle size of $0.3 \mu \mathrm{m}$. The powder has a bulk density of $0.8 \mathrm{~g} / \mathrm{cm}^{3}$ and a tap density of $1.1 \mathrm{~g} / \mathrm{cm}^{3}$. Particles morphology was observed in Scanning Electron Microscope (Field Emission Gun FEG-SEMJSM7600F, JEOL). Dispersion was achieved by adding nitric acid with a purity of $69 \mathrm{wt} \%$. Polyvinyl alcohol (PVA) diluted in deionized water $\left(35 \mathrm{wt} \%, 1.08 \mathrm{~g} / \mathrm{cm}^{3}\right.$ at $\left.23^{\circ} \mathrm{C}\right)$ was used as the binder.

Suspensions with varying solid concentrations of $\alpha$ $\mathrm{Al}_{2} \mathrm{O}_{3}$ powder were prepared using deionized water and $\mathrm{HNO}_{3}$. The basic suspension used, as reference, for most of the study contained 33 vol\% alumina particles. The powder is incorporated and dispersed using magnetic stirring for $1 \mathrm{~h}$ and then deagglomerated in ultrasonic bath for 5-15 minutes. PVA was added to the suspension using magnetic stirring. The $\mathrm{pH}$ of the $\alpha-\mathrm{Al}_{2} \mathrm{O}_{3}$ slurry is adjusted with the quantity of $\mathrm{HNO}_{3}$ and was found to settle between 5 and 6 for an acid concentration of $0.06 \mathrm{~mol} / \mathrm{L}(0.17 \mathrm{wt} \%)$.

In order to assess the influence of acid concentration and PVA on dispersion, the amount of $\mathrm{HNO}_{3}$ was varied between 0 and $0.34 \mathrm{wt} \%$ and the quantity of PVA added to the slurry between 0 and $16.48 \mathrm{wt} \%$. The maximum packing fraction was also investigated using viscosity data of slurries containing 10 to 46 vol\% of $\mathrm{Al}_{2} \mathrm{O}_{3}$ particles.

2.2. Rheological Measurements. Rheological measurements were performed using a MCR501 rheometer from AntonPaar, with concentric cylinders' geometry (27 mm bob diameter, $1.17 \mathrm{~mm}$ gap). Preliminary rheology tests have been done on the slurry in order to establish the required conditioning (preshear and rest time) to get repeatable and consistent data. It is required for suspension since flow history has a great impact on rheological measurement [26, 27]. The conditioning defined for the suspensions is a preshear of $10 \mathrm{~s}^{-1}$ during $5 \mathrm{~min}$ followed by a rest time of $5 \mathrm{~min}$. The preshear and rest time must be applied before and between every test. These conditions were defined with the reference suspension containing $33 \mathrm{vol} \%$ of $\mathrm{Al}_{2} \mathrm{O}_{3}$ particles and are valid for other particles concentration if the amount of $\mathrm{HNO}_{3}$ is enough to maintain the particles dispersed. Potential wall slip and sedimentation were verified as well and the slurry remained stable under the testing conditions. Structure rebuilt experiments were performed and the suspension retrieves its original properties almost immediately after preshear. Moreover, no thixotropy was observed as successive tests showed curves superimposed. Since the suspension is intended for an injection process, no yield stress is expected for standard slurries, verification has been done, and this point is discussed in the Results. All measurements were conducted at $23^{\circ} \mathrm{C}$. In order to prevent evaporation, mineral 
oil has been poured on top of suspension; this liquid is inert and does not interact with the measurement.

Steady shear experiments have been carried out by running loops from 0.1 to $1000 \mathrm{~s}^{-1}$ and back down to $0.1 \mathrm{~s}^{-1}$. Small amplitude oscillatory shear (SAOS) tests have been conducted from $0.1 \mathrm{~Hz}$ to $100 \mathrm{~Hz}$ with strain amplitude of $10 \%$. This amplitude of $10 \%$ is inside the linear viscoelastic (LVE) domain.

\section{Results and Discussion}

The rheological behavior of suspensions depends on a number of variables such as the particle shape, size, and distribution of particles sizes but also the interaction forces. The chemicals used in the slurry preparation have great influence on the stability of the suspension [8]. It is therefore crucial to understand how the chemicals interact with each other and with alumina particles to get an acceptable suspension for the injection process.

In this work, the same size and distribution of alumina particles were used for all slurry preparation. The particle SEM morphology presented in Figure 1 shows a fairly even distribution of irregular 3D flake particles. The morphology and the particle size greatly influence the rheological behavior of the suspension, notably at high volume fraction. The reference suspension is composed of $33 \mathrm{vol} \% \mathrm{Al}_{2} \mathrm{O}_{3}$ particles (so-called $\mathrm{B} 33$ ) and $0.17 \mathrm{wt} \% \mathrm{HNO}_{3}$. The basic quantity of PVA binder solution corresponds to $6 \%$ of the mass of the alumina particles, which is $3.79 \mathrm{wt} \%$ for the B33 suspension. It should be noted that the PVA used in this study is an aqueous solution diluted to $35 \%$ by weight, and therefore the weight percentage reported relates to the solution. The choice of the particle base concentration is justified in terms of flow, mold filling, and compaction for the injection process. The influence of dispersant, binder, and particles concentration are investigated in this study.

3.1. Influence of Acid Content. $\mathrm{B} 33$ suspensions with $\mathrm{HNO}_{3}$ varying from 0 to $0.34 \mathrm{wt} \%$ were prepared (Table 1). Figure 2 illustrates the viscosity variation with shear rate. Lower viscosity preparations show the most stable curves in the backforward loops and their flow response is more Newtonian. Similar results have been observed by other authors with ascorbic acid as dispersant [11]. In addition, there is also an overlap of the curves in Figure 2 for some acid contents $(0.17$ and $0.08 \mathrm{wt} \%)$, suggesting that there is a stability zone for the suspension. An offset between the back-forward loops for the $0.04 \mathrm{wt} \%, 0.25 \mathrm{wt} \%$, and $0.34 \mathrm{wt} \%$ suspensions may be an indication of inadequate dispersion of the alumina particles. For low percentages, the attraction forces between particles are too strong, leading to heterogeneities and possible flocculation. When the repulsive forces are too strong, aggregates can be formed and permanent precipitation will occur.

Figure 3 shows the viscosity values at $0.1 \mathrm{~s}^{-1}$ of alumina slurry as function of the acid concentration from $0 \mathrm{wt} \%$ up to $0.34 \mathrm{wt} \%$. Suspensions with $0 \mathrm{wt} \%$ and $0.01 \mathrm{wt} \%$ acid (not shown) were tested in a similar manner and a viscosity of about 1000 and $200 \mathrm{~Pa} \cdot \mathrm{s}$ was measured at $0.1 \mathrm{~s}^{-1}$. However, these suspensions are very different with a foamy aspect, contrasting with suspensions containing more than 0.04 wt $\%$ $\mathrm{HNO}_{3}$ which have a smooth and homogeneous appearance (see Figure 4). Between percentages of 0.01 and $0.04 \mathrm{wt} \%$ $\mathrm{HNO}_{3}$, there is a change in the structure of the slurry itself making measurements more difficult. These suspensions show immediate separation in a very short time just after preparation. The resulting parabolic profile of Figure 3 suggests that there is a critical range of acid concentration between 0.08 and $0.2 \mathrm{wt} \%$ where the viscosity is minimum.

When alumina particles are immersed in water, there is a hydrolysis reaction between alumina and hydroxide, and this is enhanced with $\mathrm{pH}$. In the presence of nitric acid, the hydroxyl group on the alumina surface reacts with the $\mathrm{H}+$ that come from the acid. The addition of nitric acid promotes the production of positive charge on the particles and thus repulsive forces $[8]$ :

$$
\begin{aligned}
\mathrm{Al}^{3+} & \longrightarrow \mathrm{Al}(\mathrm{OH})^{2+} \longrightarrow \mathrm{Al}(\mathrm{OH})_{2}{ }^{+} \longrightarrow \mathrm{Al}(\mathrm{OH})_{3} \\
& \longrightarrow \mathrm{Al}(\mathrm{OH})_{4}{ }^{-}
\end{aligned}
$$

The reaction of alumina particles surface (s Al-OH) with $\mathrm{H}^{+}$ of the nitric acid is

$$
\begin{aligned}
& \mathrm{HNO}_{3}+\mathrm{H}_{2} \mathrm{O} \longrightarrow \mathrm{NO}_{3}^{-}+\mathrm{H}_{3} \mathrm{O}^{+} \\
& \mathrm{s} \mathrm{Al}-\mathrm{OH}+\mathrm{H}^{+} \longrightarrow \mathrm{s} \mathrm{Al}-\mathrm{OH}_{2}{ }^{+}
\end{aligned}
$$

The objective is to obtain electrical stability within the suspension. Below the critical zone, the amount of nitric acid adsorbed on particles surface is insufficient for adequate dispersion and above this zone; the excess of acid may create aggregates and precipitates, both resulting in higher viscosities.

To obtain a uniform green body, it is necessary to disperse adequately the alumina particles in the media and the additives added to the suspension. In this manner, the interactions between the particles will be improved and controlled. Rheology is used to understand the behavior of the suspension and provides information on the interaction between the particles. Strong interactions between particles result in high viscosities and shear-thinning behavior whereas repulsion results in stable suspensions with low viscosities and eases the injection process. On the process level, having a critical acid zone rather than a critical value provides process flexibility. A variation in the critical area will not affect the quality of the final ceramic part. At the critical point, the lowest viscosity is obtained, meaning that the $\mathrm{pH}$ of the suspension is below the isoelectric point (IEP) of the oxide powder and above the acidic dissociation constant of the acidic functional group adsorbed $[8,11]$.

3.2. Influence of PVA Content. B33 slurries were prepared using PVA concentrations varying from 0 to $16.48 \mathrm{wt} \%$. Figure 5 presents the variation of steady shear viscosity with shear rate for different concentrations of PVA. The filled and empty symbols correspond to the back and forth viscosity change with shear rate. For the same PVA content, curves are superimposed and present a Newtonian behavior at low shear rate followed by a slight shear thinning starting around $10 \mathrm{~s}^{-1}$. 


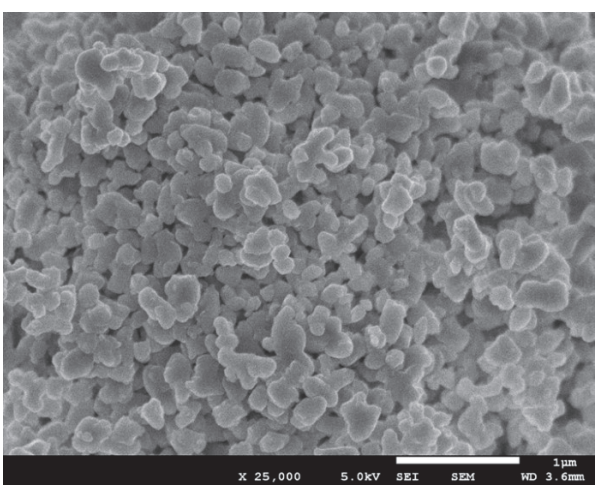

(a)

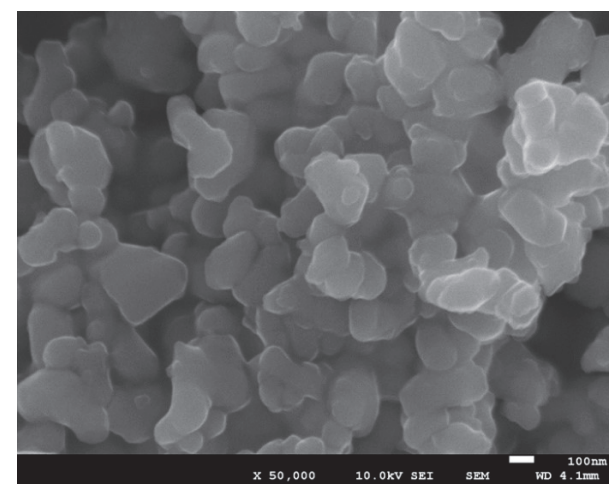

(b)

FIGURE 1: FEG-SEM micrographs of alumina particulates. Scale 1 micron (a) and $100 \mathrm{~nm}$ (b).

TABLE 1: B33 suspension preparation with change in PVA and acid content. B33 base concentration contains $0.17 \mathrm{wt} \%$ acid and $3.80 \mathrm{wt} \%$ PVA.

\begin{tabular}{|c|c|c|c|c|c|c|c|c|c|}
\hline \multirow[b]{2}{*}{$\#$} & \multicolumn{4}{|c|}{ PVA content } & \multicolumn{5}{|c|}{ Acid content } \\
\hline & $\begin{array}{c}\text { Ratio } \\
\left(\times C_{\text {base }}\right)\end{array}$ & $\begin{array}{c}\text { wt } \% \text { acid } \\
\text { in } \mathrm{H}_{2} \mathrm{O}\end{array}$ & wt $\%$ acid $^{1}$ & $w t \% \mathrm{PVA}^{1}$ & $\#$ & $\begin{array}{c}\text { Ratio } \\
\left(\times C_{\text {base }}\right)\end{array}$ & $\begin{array}{c}\text { wt } \% \text { acid } \\
\text { in } \mathrm{H}_{2} \mathrm{O}\end{array}$ & $\mathrm{wt} \% \operatorname{acid}^{1}$ & wt $\% \mathrm{PVA}^{1}$ \\
\hline B33-PVA0 & 0 & 0.51 & 0.17 & 0 & B33-AC0 & 0 & 0.00 & 0.00 & 3.80 \\
\hline B33-PVA0.5 & 0.5 & 0.51 & 0.17 & 1.93 & B33-AC0.25 & 0.25 & 0.13 & 0.04 & 3.80 \\
\hline B33 (ref) & 1 & 0.51 & 0.17 & 3.80 & B33-AC0.5 & 0.5 & 0.26 & 0.08 & 3.80 \\
\hline B33-PVA2 & 2 & 0.51 & 0.16 & 7.31 & B33 (ref) & 1 & 0.51 & 0.17 & 3.80 \\
\hline \multirow[t]{2}{*}{ B33-PVA5 } & 5 & 0.51 & 0.15 & 16.48 & B33-AC1.5 & 1.5 & 0.76 & 0.25 & 3.80 \\
\hline & & & & & B33-AC2 & 2 & 1.02 & 0.33 & 3.80 \\
\hline
\end{tabular}

$C_{\text {base }}$ : reference formulation, with base $=$ PVA or acid. Reference formula corresponds to 1 in ratio column; ${ }^{1}$ percentage based on total weight of the slurry.

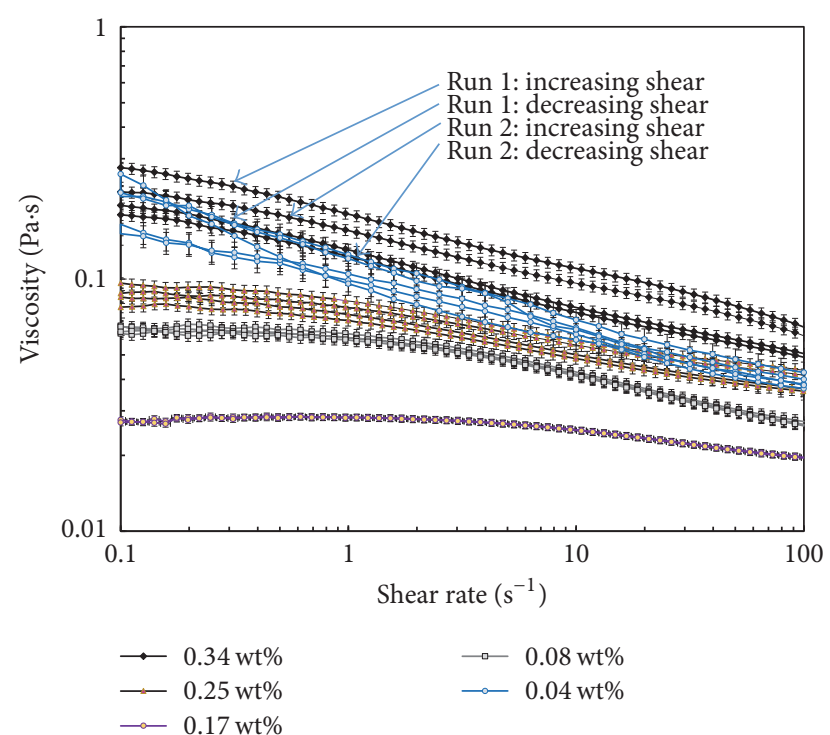

FIGURE 2: Viscosity versus shear rate for two consecutive backforward loops for B33 slurries with varied acid content from 0.04 to $0.34 \mathrm{wt} \%$.

As expected, an increase of viscosity with increasing PVA content is observed. For the highest concentration of PVA (16.48 wt\%), a bump appears after the Newtonian plateau. It could be associated with a possible change of dispersion

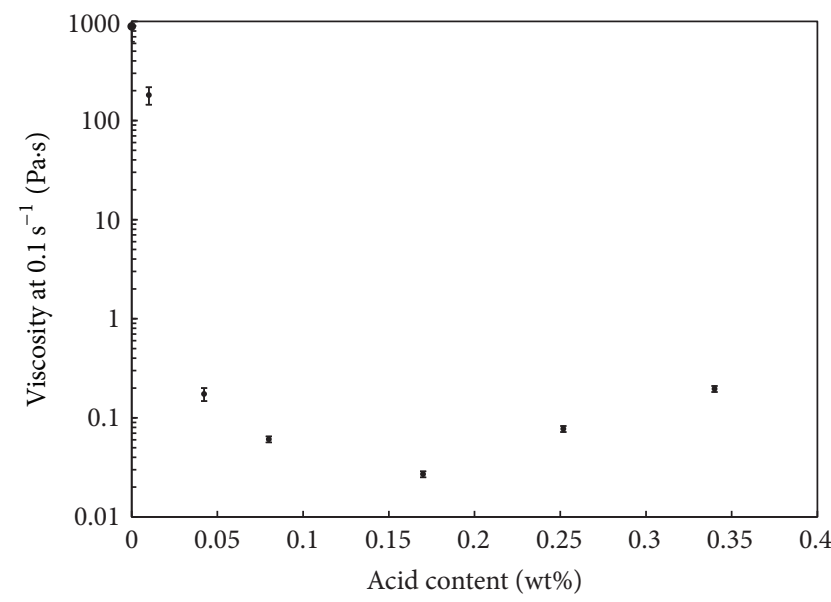

Figure 3: Viscosity at $0.1 \mathrm{~s}^{-1}$ shear rate versus acid content for B33 slurries with varied acid content from 0 to $0.34 \mathrm{wt} \%$.

state due to an overabundance of PVA, sedimentation, or the beginning of a phase separation. This illustrates the fact that there is a threshold PVA content, which does not affect the dispersion while allowing particles to adhere adequately to form the ceramic cake.

In order to understand the combined effect of PVA and the concentration of the slurry, suspensions containing 25 to 46 vol\% of particles with and without PVA were prepared. For 
TABLE 2: Different alumina slurries with particulates varying from 10 to 46 vol\%. Preparations with and without PVA. Acid content of 0.51 wt $\%$ in $\mathrm{H}_{2} \mathrm{O}$ for all slurries and PVA content of $6 \mathrm{wt} \%$ of alumina particles for slurries with PVA.

\begin{tabular}{|c|c|c|c|c|c|c|c|c|}
\hline \multirow{2}{*}{ \# } & \multirow{2}{*}{ vol $\%$ alumina } & \multirow{2}{*}{$\mathrm{wt} \%$ acid in $\mathrm{H}_{2} \mathrm{O}$} & \multicolumn{3}{|c|}{ With PVA (6\% wt. alumina) } & \multicolumn{3}{|c|}{ No PVA } \\
\hline & & & wt $\%$ acid $^{1}$ & wt $\%$ alumina ${ }^{1}$ & $\mathrm{wt} \% \mathrm{PVA}^{1}$ & $\mathrm{wt} \% \operatorname{acid}^{1}$ & wt $\%$ alumina $^{1}$ & wt $\% \mathrm{PVA}^{1}$ \\
\hline - & Media & 0.51 & 0.51 & 0 & 0 & 0.51 & 0 & 0 \\
\hline $\mathrm{B} 10$ & 10 & 0.51 & 0.35 & 29.69 & 1.78 & 0.36 & 30.23 & 0 \\
\hline B25 & 25 & 0.51 & 0.21 & 54.67 & 3.28 & 0.22 & 56.52 & 0 \\
\hline B33 & 33 & 0.51 & 0.17 & 63.27 & 3.80 & 0.18 & 65.76 & 0 \\
\hline B40 & 40 & 0.51 & 0.14 & 69.22 & 4.15 & 0.14 & 72.22 & 0 \\
\hline B46 & 46 & 0.51 & 0.11 & 73.48 & 4.41 & 0.11 & 76.86 & 0 \\
\hline
\end{tabular}

${ }^{1}$ Percentage based on total weight of the slurry.

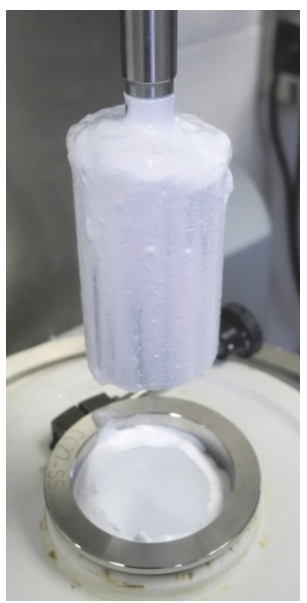

(a)

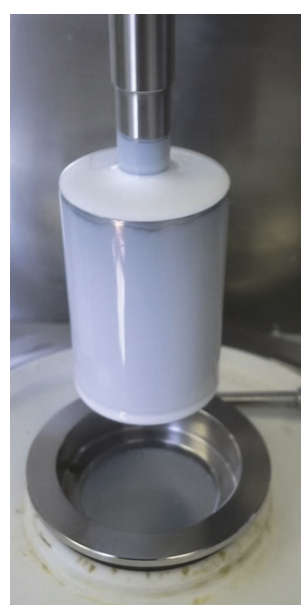

(b)
Figure 4: Foaming structure for B33 slurries with low acid content of 0 and $0.01 \mathrm{wt} \%$ (a) and liquid-like B33 slurries with acid content higher than $0.04 \mathrm{wt} \%$ (b).

suspensions containing PVA, the amount of polymer solution corresponds to $6 \%$ of the mass of the alumina particles. This ensures that the ratio of adsorption between particles and PVA is constant, assuming that alumina particles are well dispersed into the media. These suspensions are listed in Table 2 and Figure 6 presents the variation of viscosity with shear rate for B10 to B46 slurries. The filled symbols correspond to the suspensions with PVA whereas the empty symbols correspond to slurry without PVA. Generally, for suspensions with PVA, an increase of the particle concentration leads to an increase of the viscosity from $0.01 \mathrm{~Pa} \cdot \mathrm{s}$ for B25 to $1.3 \mathrm{~Pa} \cdot \mathrm{s}$ for B46. For low charge suspensions with PVA, the behavior is Newtonian. Towards $40 \mathrm{vol} \%$, the shear-thinning behavior begins to be more pronounced and at 46 vol\% the Newtonian plateau disappears and a shear-thinning behavior is observed over the whole range of the shear rate. The B46 suspension with no PVA shows a yield stress. It was evaluated at $1.9 \mathrm{~Pa}$ using the Hershel-Bulkley model (not shown here). However, the B46 no PVA suspension is a limit condition and is not suitable for processing. Slurries with lower percentages of alumina particles show a typical power-law flow behavior.

For suspensions B33 and B25, those that do not contain PVA have a lower viscosity than those with PVA. The viscosity

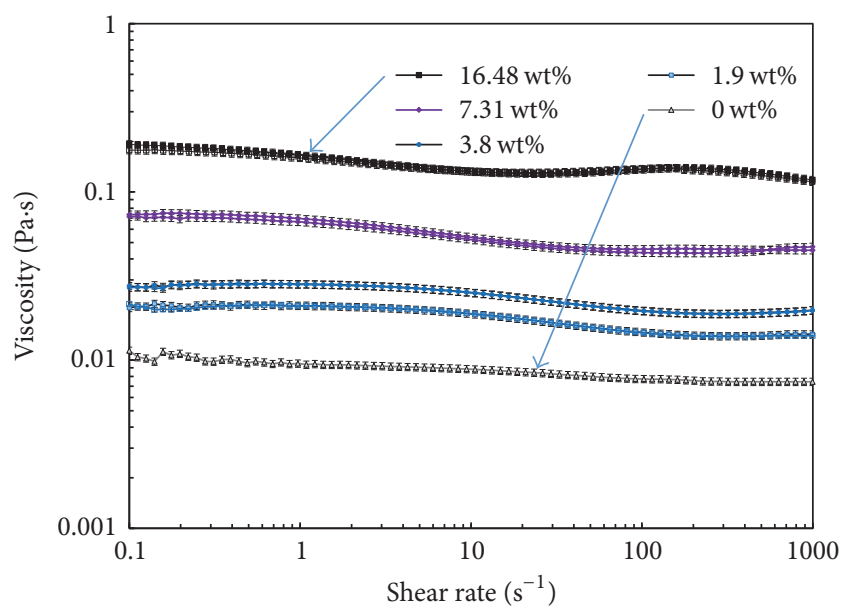

FIGURE 5: Viscosity versus shear rate for back-forward loop for B33 slurries with varied PVA content from 0 to $16.48 \mathrm{wt} \%$.

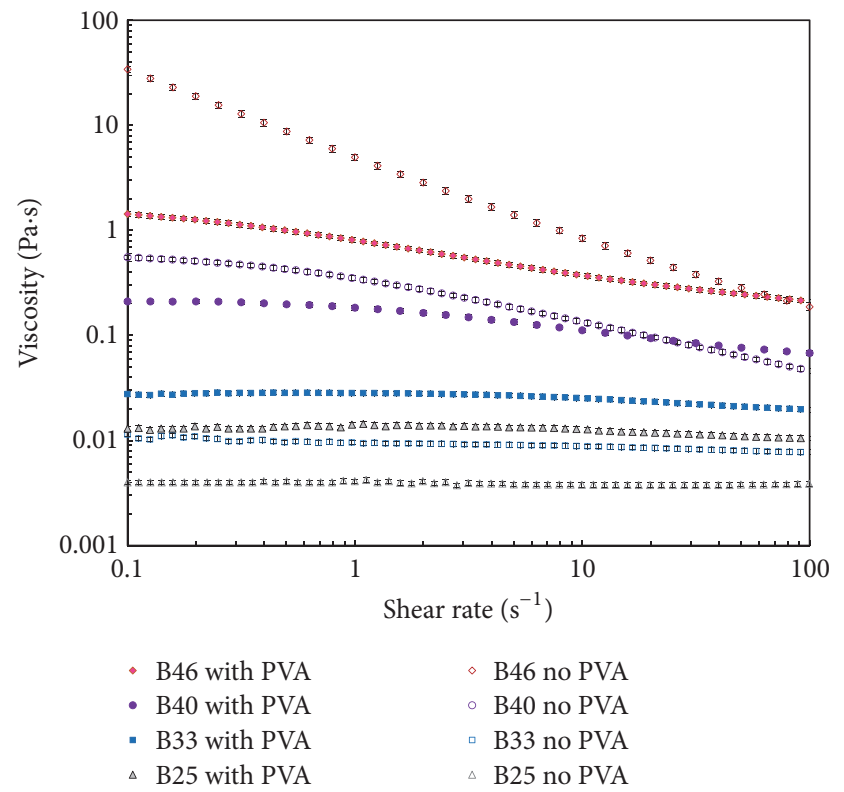

FIGURE 6: Viscosity versus shear rate for slurries containing 25 to $46 \mathrm{vol} \%$ of alumina particulates. Slurries with and without PVA. PVA content of $6 \%$ of weight of particulates for slurries containing PVA. 
of these suspensions with no PVA is low (0.00941 Pa.s for B33 no PVA and $0.00420 \mathrm{~Pa} \cdot \mathrm{s}$ for B25 no PVA) and close to that of the corresponding suspensive media with PVA (0.00148 Pa.s for B33 and 0.00139 Pa.s for B25). Thus, the viscosity of the media has an influence on the lowest charged suspensions. The increase of viscosity related to the addition of PVA in the media is of the order of $200 \%$ for B33 and $240 \%$ for B25. For highly charged suspensions B40 and B46, the addition of PVA results in a change in the rheology behavior of the suspension from a strong shear-thinning behavior to a weak shear thinning approaching Newtonian.

The quantity of PVA is adjusted according to the dry mass in alumina ( $6 \%$ of mass of particles); thus the ratio remains constant. Since PVA comes from an aqueous solution $35 \mathrm{wt} \%$, its addition to the slurry slightly lowers the suspension viscosity and decreases the particle loading slightly (in the order of 3-4\%). On the other hand, all suspensions were prepared using the same acidified water (same concentration of $\mathrm{HNO}_{3}$ dispersant). This means that there is probably a small excess of $\mathrm{HNO}_{3}$ for B25 suspension while B33 suspension exhibits an optimized concentration of nitric acid (Figure 3). For B40 and B46 suspensions, this concentration is less and this leaves room for additional adsorption of PVA on the particles. For alumina suspensions containing both dispersant and PVA binder, it was reported that the dispersant is first adsorbed on particle surface; then the binder coats the rest of the particle $[13,16,22]$. Depending on the dispersant/binder ratio, the rheology of the slurry changes from a more or less shear thinning to Newtonian behavior [16].

Polyvinyl alcohol (PVA) is prepared by hydrolysis of polyvinyl acetate (PVAc), usually leaving a small fraction of unhydrolysed acetate groups in the macromolecule chain structure that contribute to PVA stabilization, preventing depolymerisation [28, 29]. The PVA is adsorbed on the surface of the alumina particles by hydrogen bonding of its $-\mathrm{OH}$ functional groups. However, in the case of partially hydrolyzed PVA, which is the PVA used in this study, the adsorption on the alumina particle surface might be preferential for the acetate groups $-\mathrm{OCOCH}_{3}$ rather than the hydroxyl groups $[29,30]$. These groups have great influence on the adsorption properties of PVA, providing a chemical conformation of the polymer with a structure with more loops and tails adsorbed better to the surface of the alumina particle [30]. Acetate groups are also sensitive to $\mathrm{pH}$ with the level of interactions increasing with $\mathrm{pH}[29,31]$. Wiśniewska et al. [29] have demonstrated that there is a stability $\mathrm{pH}$ range between 3 and 6 for alumina suspension and that beyond the PVA is more stretched and thus the adsorption of the polymer chain is on few particles, causing bridging flocculation of suspension. The alumina suspension in this study has a $\mathrm{pH}$ of 5-6, in the limits of stability.

Combining the results from Figure 5 on the impact of PVA concentration for B33 slurry with those of Figure 6 presenting the impact of similar ratio of PVA/alumina for B25 to B46 slurries, it came out that a threshold of $3 \%$ of mass of alumina particles can be set for the PVA content. This value corresponds to only $1.9 \mathrm{wt} \%$ for B33 slurry suggesting that low viscosity is achievable up to 40 vol\% alumina by using the optimal amount of PVA. However, slurry with 33 vol\% of particles with PVA which exhibits a Newtonian behavior combined to a low viscosity represents the best potential with respect to the processability of the oxide/oxide ceramic.

At low shear rate, the interparticles forces and the Brownian motion dominate whereas the hydrodynamic forces predominate and overcome the interparticles interactions at higher shear rates leading to a decrease of the viscosity. For more concentrated suspensions, the separation distance between particles is narrowed and the probability to aggregate increases due to apparition of the Van der Waals attractive forces [8]. This explains the shear-thinning behavior observed for the highly charged suspensions (Figure 6). This rheological behavior was observed for similar systems using oxide nanoparticles in aqueous media, the shear thinning being enhanced by particle loading [12].

The role of PVA is to increase the strength of the green body and it therefore acts as the binder in the alumina suspension. PVA coats the surface of the particles and improves the adhesion between the particles during the formation of the ceramic cake. PVA is water-soluble and is removed from the green body during drying and sintering process. However, its quantity needs to be optimized in order to limit the formation of macroporosities during the sintering process.

3.2.1. SAOS Experiments. In order to understand the combined impact of acid and PVA on the structure of the suspension, Small Amplitude Oscillatory Shear (SAOS) experiments were performed on B33 slurry. Frequency sweep tests were performed on B33 samples with different acid and PVA contents listed in Table 1. Figures 7 and 8 present the change of the loss modulus $G^{\prime \prime}$ with frequency for B33 suspensions with different acid and PVA contents, respectively. It can be observed that there is no elastic response, which is consistent with the absence of structure in the suspension. The suspension remains viscous over the entire frequency range tested, and so the energy remains dissipated. The main reason is that slurry remains liquid even with $16.48 \mathrm{wt} \%$ PVA solution and there is no development of a gel structure. The loss modulus increases progressively with the frequency and an abrupt change of slope is observed towards $10 \mathrm{~Hz}(6 \mathrm{rad} / \mathrm{s})$. The friction between the alumina particles at high frequencies can explain this increase of the loss modulus. The friction increases energy dissipation in the slurry and is only related to the particles. A direct influence of nitric acid and PVA was not observed.

3.3. Mixing Equipment on Dispersion. The standard suspension preparation process consists of incorporating different materials in the aqueous media using mechanical agitation with magnetic stirrer for 1 hour followed by an exposure to ultrasound for 5-15 minutes. This type of process deagglomeration of the alumina particles has been widely used by several authors $[16,17,20,21,24]$. Preparation with high shear mixer (HSM) is also increasingly used in particular for dispersion of nanoclays $[32,33]$. The HSM breaks aggregates by passing the suspension through a small capillary at very high pressure. The B33 suspensions were prepared in the usual manner and using HSM. Figure 9 shows the changes in viscosity as a function of the shear rate for the various 


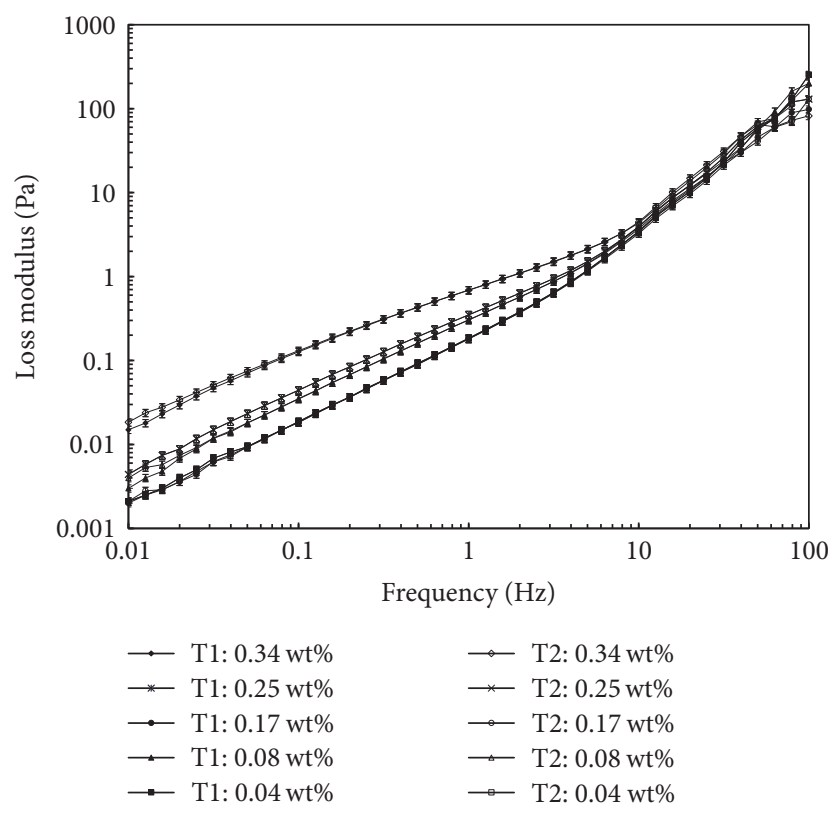

FIGURE 7: Loss modulus versus frequency for B33 slurries containing varied acid content from 0.04 to $0.34 \mathrm{wt} \%$. Two tests illustrated $\mathrm{T} 1$ and $\mathrm{T} 2$.

mixtures. The term HSM $1 \mathrm{p}$ corresponds to 1 pass in the HSM, 5 p to 5 passes, and so on. If 1 and 2 passes in the HSM decrease the viscosity of the B33 slurry, which is an indicator of a better dispersion [8, 11, 14], 5 passes' HSM shows similar results when compared to regular US mix. The viscosity continues to increase after 10 passes. This increase in viscosity can be related to water evaporation associated with overheat in the HSM. However, the viscosity stays in the same decade, varying from 0.025 to $0.04 \mathrm{~Pa} \cdot \mathrm{s}$, which is not sufficiently significant at the process level to change of the mixing procedure.

3.4. Maximum Packing Factor. In the suspension, there is a moment where the loading level in particles reaches a maximum. This level defines the maximum packing beyond which the viscosity of the suspension tends to infinite. The shape, particle surface, and the aspect ratio (the ratio between the diameter and the length of the particles) are important aspects to consider when determining the maximum packing. When this ratio increases, the maximum packing tends to decrease. Irregularities on the particle surface tend to decrease the value of the maximum packing, which is the case in this study, with the 3D irregular flake shape of alumina particles (Figure 1). Metzner [34] noted a value of $44 \mathrm{vol} \%$ for a rough spherical crystal compared to 68 vol\% for smooth spheres.

The maximum packing factor was evaluated for the alumina slurry with and without PVA (Table 2) by using an empirical expression originated by Maron and Pierce:

$$
\eta_{r}=\left(1-\frac{\Phi}{A}\right)^{-2}
$$

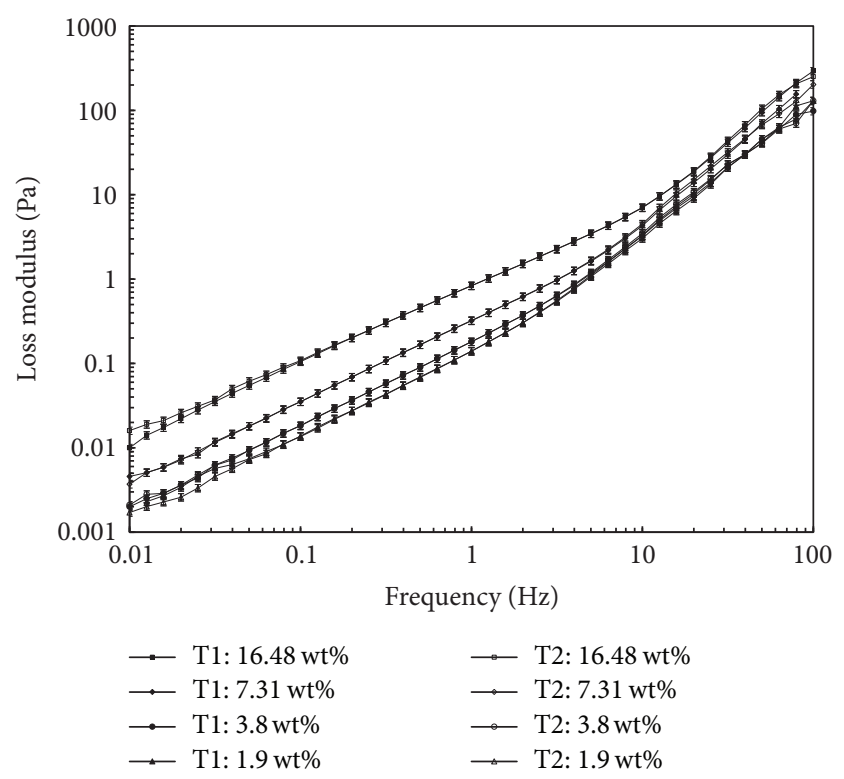

FIGURE 8: Loss modulus versus frequency for B33 slurries containing varied PVA content from 0 to $16.48 \mathrm{wt} \%$. Two tests illustrated $\mathrm{T} 1$ and T2.

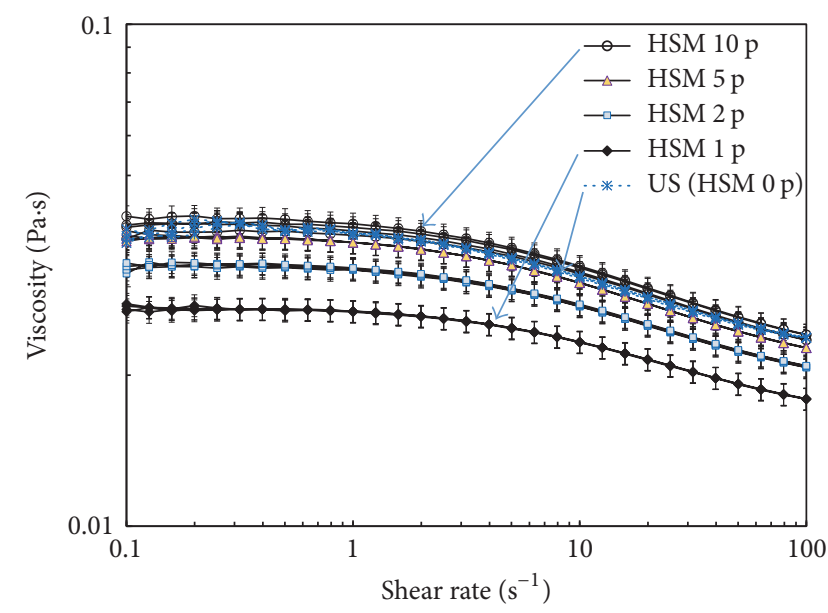

FIGURE 9: Viscosity versus shear rate for B33 base slurry (0.17 wt\% acid and $3.80 \mathrm{wt} \%$ PVA) preparation using HSM. Consecutive pass in HSM using the same mixture from 1 pass to 10 passes. Slurry with 0 passes corresponds to US.

where $\eta_{r}$ is the ratio of the suspension viscosity over the viscosity of the suspending media, evaluated at the same shear stress [35]. This equation allows the determination of an empirical constant $A$ which can be associated with the maximum volumetric packing factor $\Phi_{M}$ of the suspension. Equation (3) can be rewritten as

$$
\sqrt{\frac{1}{\eta_{r}}}=1-\frac{\Phi}{\Phi_{M}}
$$

Relative viscosities of suspensions B10 to B40 are shown in Figure 10. Neither B46 suspensions nor B40 without PVA show Newtonian area, and therefore these slurries were not 


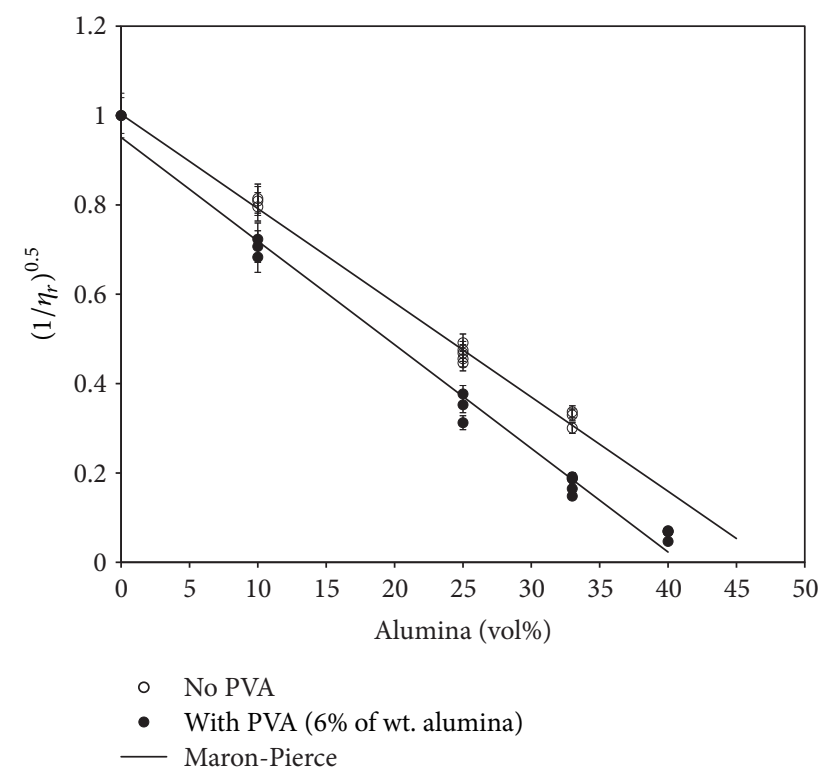

FIGURE 10: Relative viscosity versus alumina concentration for slurries with and without PVA containing 0 to $40 \mathrm{vol} \%$ of alumina particulates. Modeling using Maron and Pierce equation.

presented in Figure 10. The maximum packing $\Phi_{M}$ in (4) is calculated from the slope of the linear fitting of the data. The coefficient of determination $R^{2}$ between the experimental data and the model is 0.9946 for no PVA suspensions and 0.9844 for suspensions containing PVA. There is a slight difference in slopes for suspension with and without PVA. A maximum packing of 43.1 vol\% was calculated for slurries with PVA and 47.4 vol\% for slurries without PVA. This confirms that a suspension up to $40 \mathrm{vol} \%$ particles can be easily prepared and meet the requirements in terms of packing. At this concentration, the slurry is still liquid and injectable.

The PVA is adsorbed on the surface of the particles, which are already dispersed by nitric acid. The same amount of $\mathrm{HNO}_{3}$ was used for all the suspensions. It is likely that the PVA has an impact on the dispersion of particles as shown by the difference of $4.3 \%$ between $\Phi_{M}$ of suspensions with and without PVA, confirming results discussed above (PVA section). However, this difference is small considering that the PVA content corresponds to $6 \%$ of the mass of particles. This confirms that there is probably a large excess of polymer and it is not necessary to put as much for the cohesion of particles during drying and sintering; only a fraction of the polymer is adsorbed on particles surface. These results on the influence of the PVA are added to the previous ones (Figures 5 and 6) showing its influence on the viscosity, the rheology behavior, and the particle loading of the slurry. Given that PVA is the binder that allows the ceramic particles to adhere, a minimum of $3 \%$ of the mass of particles is necessary to ensure a ceramic cake that holds. This quantity was confirmed visually by the fact that cakes with less PVA collapse. This percentage of $3 \%$ makes it possible to have a stable Newtonian rheological behavior and a low viscosity of $0.03 \mathrm{~Pa} \cdot \mathrm{s}$ for B33 slurry that ease the injection process and fiber impregnation.

\section{Conclusions}

Different $\mathrm{Al}_{2} \mathrm{O}_{3}$ suspensions have been studied with respect to their composition and concentration. The analysis was motivated by the need to provide valuable data to improve the processing of oxide/oxide composites by flexible injection. The formulation is simple and requires the use of an acidic dispersant and a binder. The slurry can be processed by using mechanical stirring and ultrasounds for dispersion. The following main results were obtained:

(i) Based on the rheology analysis, it was found that there is a critical concentration of $\mathrm{HNO}_{3}$ between 0.08 and $0.2 \mathrm{wt} \%$ that ensures a stable dispersion and a lower viscosity.

(ii) A concentration of PVA binder of $3 \%$ of particle mass is enough to ensure a Newtonian behavior and low viscosity and ease the injection of suspension charged up to $40 \mathrm{vol} \%$ particulates.

(iii) The SAOS measurements show that there is no structure development with increased frequency. Increasing loss modulus is consistent with energy dissipation occurring over the entire frequency range.

(iv) The maximum packing fraction is 47.4 vol\% alumina for suspension without PVA and $43.1 \mathrm{vol} \%$ for suspensions with PVA content corresponding to 6\% mass of particles. The small difference in slope suggests that the polymer is in excess in the suspension. Reducing this quantity by half should be sufficient to reach suitable viscosity for injection molding.

\section{Conflicts of Interest}

The authors declare that there are no conflicts of interest regarding the publication of this paper.

\section{Acknowledgments}

This research was supported by the Natural Sciences and Engineering Research Council of Canada (NSERC). The authors are also grateful to the industrial partner Groupe Safran for supporting this project.

\section{References}

[1] M. Parlier and M. H. Ritti, "State of the art and perspectives for oxide/oxide composites," Aerospace Science and Technology, vol. 7, no. 3, pp. 211-221, 2003.

[2] P. Colomban and G. Gouadec, "The ideal ceramic-fibre/oxidematrix composite: how to reconcile antagonist physical and chemical requirements?" Annales de Chimie: Science des Materiaux, vol. 30, no. 6, pp. 673-688, 2005.

[3] F. W. Zok, "Developments in oxide fiber composites," Journal of the American Ceramic Society, vol. 89, no. 11, pp. 3309-3324, 2006.

[4] J. H. Weaver, J. Rannou, M. A. Mattoni, and F. W. Zok, "Interface properties in a porous-matrix oxide composite," Journal of the American Ceramic Society, vol. 89, no. 9, pp. 2869-2873, 2006. 
[5] C. G. Levi, J. Y. Yang, B. J. Dalgleish, F. W. Zok, and A. G. Evans, "Processing and performance of an all-oxide ceramic composite," Journal of the American Ceramic Society, vol. 81, no. 8, pp. 2077-2086, 1998.

[6] M. Podgorski, C. Billotte Cabre, B. Dambrine, L. Molliex, E. Ruiz, and S. Turenne, "Method for manufacturing part made of composite material," 2016.

[7] M. Podgorski, C. Billotte Cabre, B. Dambrine, L. Molliex, E. Ruiz, and S. Turenne, "Method for manufacturing a refractory part made of composte material," 2016.

[8] G. V. Franks and Y. Gan, "Charging behavior at the aluminawater interface and implications for ceramic processing," Journal of the American Ceramic Society, vol. 90, no. 11, pp. 33733388, 2007.

[9] P. Tomasik, C. H. Schilling, R. Jankowiak, and J.-C. Kim, “The role of organic dispersants in aqueous alumina suspensions," Journal of the European Ceramic Society, vol. 23, no. 6, pp. 913919, 2003.

[10] M. Parlier, M. H. Ritti, and A. Jankowiak, "Potential and perspectives for oxide/oxide composites," Journal Aerospace Lab, vol. 3, pp. 1-11, 2011.

[11] S. Çinar and M. Akinc, "Ascorbic acid as a dispersant for concentrated alumina nanopowder suspensions," Journal of the European Ceramic Society, vol. 34, no. 8, pp. 1997-2004, 2014.

[12] S. Çinar, D. D. Anderson, and M. Akinc, "Influence of bound water layer on the viscosity of oxide nanopowder suspensions," Journal of the European Ceramic Society, vol. 35, no. 2, pp. 613622, 2015 .

[13] M. N. Rahaman, "Science of colloidal processing," in Ceramic Processing and Sintering, pp. 181-245, Marcel Dekker, Inc., New York, NY, USA, 2003.

[14] N. Kiratzis and P. F. Luckham, "Rheological behavior of stabilized aqueous alumina dispersions in presence of hydroxyethyl cellulose," Journal of the European Ceramic Society, vol. 18, no. 7, pp. 783-790, 1998.

[15] N. E. Kiratzis and P. F. Luckham, "The rheology of aqueous alumina suspensions in the presence of hydroxyethylcellulose as binder," Journal of the European Ceramic Society, vol. 19, no. 15, pp. 2605-2612, 1999.

[16] M. R. Ben Romdhane, S. Baklouti, J. Bouaziz, T. Chartier, and J.-F. Baumard, "Dispersion of $\mathrm{Al}_{2} \mathrm{O}_{3}$ concentrated suspensions with new molecules able to act as binder," Journal of the European Ceramic Society, vol. 24, no. 9, pp. 2723-2731, 2004.

[17] Y.-K. Leong, "Role of molecular architecture of citric and related polyacids on the yield stress of $\alpha$-alumina slurries: inter- and intramolecular forces," Journal of the American Ceramic Society, vol. 93, no. 9, pp. 2598-2605, 2010.

[18] K. Sato, H. Yilmaz, A. Ijuin, Y. Hotta, and K. Watari, "Acetic acid mediated interactions between alumina surfaces," Applied Surface Science, vol. 258, no. 8, pp. 4011-4015, 2012.

[19] L. F. G. Setz, A. C. Silva, S. C. Santos, S. R. H. Mello-Castanho, and M. R. Morelli, "A viscoelastic approach from $\alpha-\mathrm{Al}_{2} \mathrm{O}_{3}$ suspensions with high solids content," Journal of the European Ceramic Society, vol. 33, no. 15-16, pp. 3211-3219, 2013.

[20] L. Stappers, L. Zhang, O. Van der Biest, and J. Fransaer, "The effect of electrolyte conductivity on electrophoretic deposition," Journal of Colloid and Interface Science, vol. 328, no. 2, pp. 436446, 2008.

[21] F. Chabert, D. E. Dunstan, and G. V. Franks, "Cross-linked polyvinyl alcohol as a binder for gelcasting and green machining," Journal of the American Ceramic Society, vol. 91, no. 10, pp. 3138-3146, 2008.
[22] S. Baklouti, T. Chartier, and J. F. Baumard, "Binder distribution in spray-dried alumina agglomerates," Journal of the European Ceramic Society, vol. 18, no. 14, pp. 2117-2121, 1998.

[23] A. L. Ahmad, M. R. Othman, and N. F. Idrus, "Synthesis and characterization of nano-composite alumina-titania ceramic membrane for gas separation," Journal of the American Ceramic Society, vol. 89, no. 10, pp. 3187-3193, 2006.

[24] M. A. Huha and J. A. Lewis, "Polymer effects on the chemorheological and drying behavior of alumina-poly(vinyl alcohol) gelcasting suspensions," Journal of the American Ceramic Society, vol. 83, no. 8, pp. 1957-1963, 2000.

[25] K. Livanov, H. Jelitto, B. Bar-On, K. Schulte, G. A. Schneider, and D. H. Wagner, "Tough alumina/polymer layered composites with high ceramic content," Journal of the American Ceramic Society, vol. 98, no. 4, pp. 1285-1291, 2015.

[26] C. Billotte, P. J. Carreau, and M.-C. Heuzey, "Rheological characterization of a solder paste for surface mount applications," Rheologica Acta, vol. 45, no. 4, pp. 374-386, 2006.

[27] G. P. Citerne, P. J. Carreau, and M. Moan, "Rheological properties of peanut butter," Rheologica Acta, vol. 40, no. 1, pp. 86-96, 2001.

[28] S. Baklouti, J. Bouaziz, T. Chartier, and J.-F. Baumard, "Binder burnout and evolution of the mechanical strength of drypressed ceramics containing poly (vinyl alcohol)," Journal of the European Ceramic Society, vol. 21, no. 8, pp. 1087-1092, 2001.

[29] M. Wiśniewska, S. Chibowski, T. Urban, and D. Sternik, "Investigation of the alumina properties with adsorbed polyvinyl alcohol," Journal of Thermal Analysis and Calorimetry, vol. 103, no. 1, pp. 329-337, 2011.

[30] S. Chibowski, M. Paszkiewicz, and M. Krupa, "Investigation of the influence of the polyvinyl alcohol adsorption on the electrical properties of $\mathrm{Al}_{2} \mathrm{O}_{3}$-solution interface, thickness of the adsorption layers of PVA," Powder Technology, vol. 107, no. 3, pp. 251-255, 2000.

[31] D. Santhiya, S. Subramanian, K. A. Natarajan, and S. G. Malghan, "Surface chemical studies on the competitive adsorption of poly(acrylic acid) and poly(vinyl alcohol) onto alumina," Journal of Colloid and Interface Science, vol. 216, no. 1, pp. 143153, 1999.

[32] F. Bensadoun, N. Kchit, C. Billotte, S. Bickerton, F. Trochu, and E. Ruiz, "A study of nanoclay reinforcement of biocomposites made by liquid composite molding," International Journal of Polymer Science, vol. 2011, Article ID 964193, 10 pages, 2011.

[33] F. Bensadoun, N. Kchit, C. Billotte, F. Trochu, and E. Ruiz, "A comparative study of dispersion techniques for nanocomposite made with nanoclays and an unsaturated polyester resin," Journal of Nanomaterials, vol. 2011, Article ID 406087, 2011.

[34] A. B. Metzner, "Rheology of suspensions in polymeric liquids," Journal of Rheology, vol. 29, no. 6, pp. 739-775, 1985.

[35] A. J. Poslinski, M. E. Ryan, R. K. Gupta, S. G. Seshadri, and F. J. Frechette, "Rheological behavior of filled polymeric systems I. Yield stress and shear-thinning effects," Journal of Rheology, vol. 32, no. 7, pp. 703-735, 1988. 

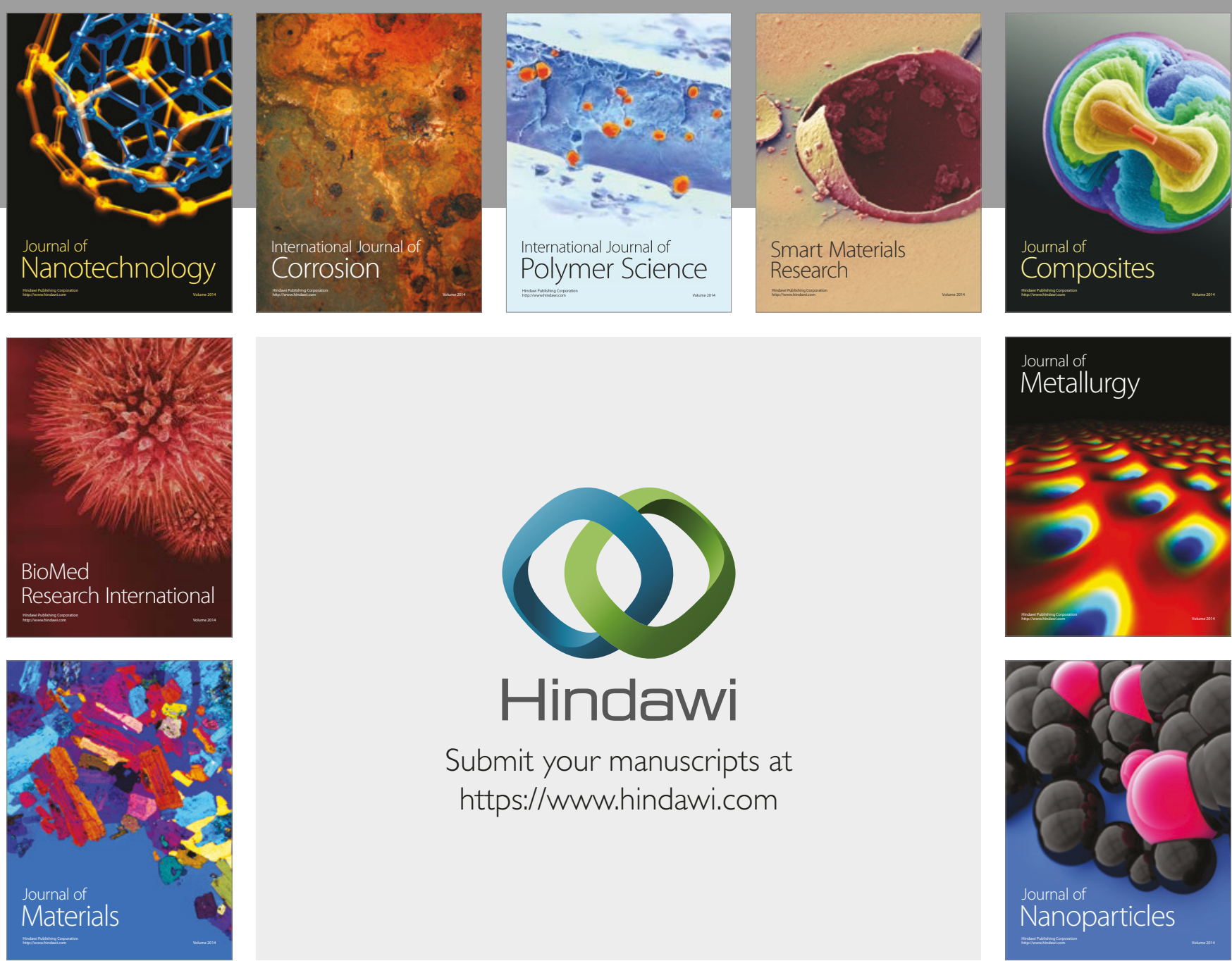

\section{Hindawi}

Submit your manuscripts at

https://www.hindawi.com
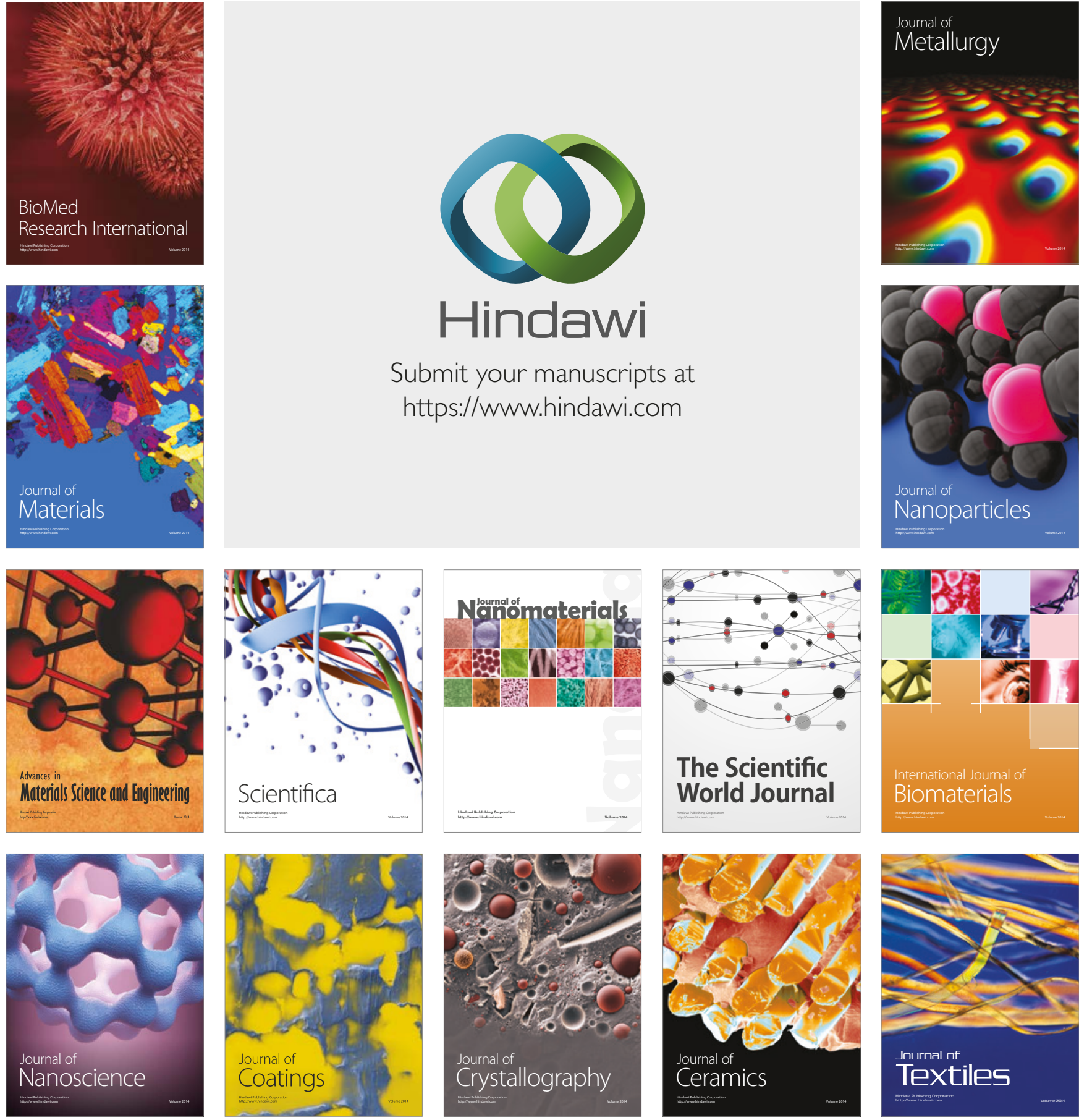

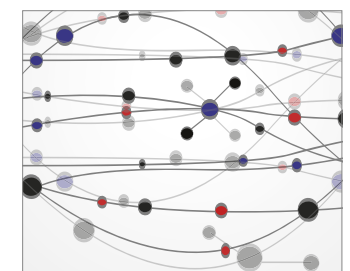

The Scientific World Journal
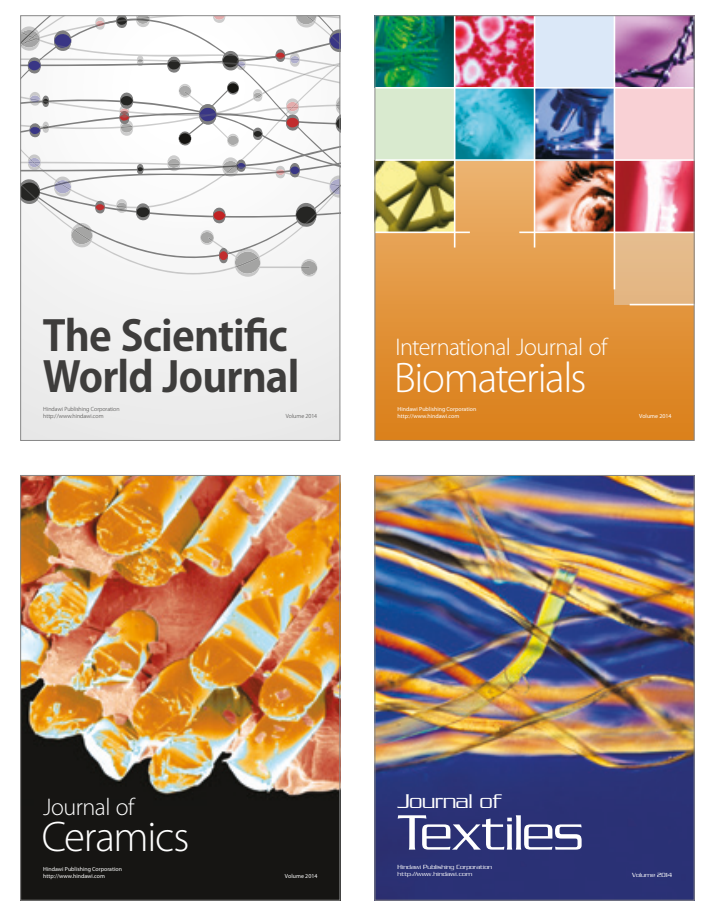